\title{
Analisis Faktor-faktor yang Mempengaruhi Produksi dan Pendapatan Petani Jeruk Siam di Desa Sukajulu Kecamatan Barusjahe Kabupaten Karo
}

\author{
${ }^{1}$ Cyprianus PH. Saragi*, ${ }^{2}$ Ramses Simbolon* , ${ }^{3}$ Putri Camelia Tarigan \\ ${ }^{1,2}$ Program Studi Agribisnis, Fakultas Pertanian, Unika Santo Thomas \\ Email: "Cyprianus.phs07@gmail.com
}

\begin{abstract}
Abstrak
Tanaman jeruk merupakan salah satu komoditas hortikultura. Penelitian ini bertujuan mengetahui faktorfaktor yang mempengaruhi produksi jeruk dan pendapatan bersih perhektar pertahun usahatani jeruk. Data yang digunakan dalam penelitian ini data primer dan data sekunder. Data primer diperoleh dari wawancara langsung dengan petani jeruk melalui survey kuesioner yang telah dipersiapkan dan data sekunder diperoleh melalui instansi terkait seperti, BPS Tanah Karo, Dinas Pertanian, dan situs-situs internet. Koefisien determinasi $\left(R^{2}\right)$ sebesar 0,948 menunjukkan bahwa 94,8\% variasi variabel dependen (produksi) usahatani jeruk siam dapat dijelaskan oleh variasi variabel independen yang terdapat dalam model. Sedangkan sisanya sebesar 5,2\% variasi variabel dependen dipengaruhi oleh variasi variable independen lain diluar model. Secara serempak variabel independen yaitu luas panen $\left(\mathrm{X}_{1}\right)$, pupuk NPK $\left(\mathrm{X}_{2}\right)$, pupuk kandang $\left(\mathrm{X}_{3}\right)$, insektisida Royal Cyper $\left(\mathrm{X}_{4}\right)$, insektisida Dafat $\left(\mathrm{X}_{5}\right)$ dan tenaga kerja $\left(\mathrm{X}_{6}\right)$ berpengaruh secara signifikan terhadap variabel dependen yaitu produksi jeruk siam (Y). Pendapatan bersih usahatani jeruk siam sebesar Rp.31.309.641/ha/tahun.
\end{abstract}

Kata kunci: Estimasi Fungsi Produksi dan Pendapatan Usahatani Jeruk Siam.

\begin{abstract}
Citrus plants are one of the horticultural commodities. This study aims to determine the factors that affect citrus production and annual net income per hectare of citrus farming. The data used in this study are primary data and secondary data. Primary data was obtained from direct interviews with citrus farmers through a questionnaire survey that had been prepared and secondary data was obtained through related agencies such as BPS Tanah Karo, Department of Agriculture, and internet sites. The coefficient of determination ( $R 2)$ of 0.948 indicates that $94.8 \%$ of the variation in the dependent variable (production) of Siamese citrus farming can be explained by the variation of the independent variables contained in the model. While the remaining $5.2 \%$ of the variation of the dependent variable is influenced by the variation of the variable other independent outside the model. Simultaneously the independent variables, namely harvested area (X1), NPK fertilizer (X2), manure (X3), Royal Cyper insecticide (X4), Dafat insecticide (X5) and labor (X6) significantly affected the dependent variable, namely citrus production. conjoined $(Y)$. The net income of Siamese citrus farming is Rp. 31,309,641/ha/year.
\end{abstract}

Keywords: Estimasi Fungsi Produksi dan Pendapatan Usahatani Jeruk Siam.

\section{PENDAHULUAN}

Indonesia adalah negara agraris dimana sebagian besar masyarakat bekerja sebagai petani untuk memenuhi kebutuhan hidup serta sebagai sumber pendapatan. Selain itu sektor pertanian merupakan andalan sebagai penyumbang devisa Negara, termasuk pertanian di bidang usahatani jeruk. Pertanian tidak hanya identik dengan sawah, melainkan ada subsektor lain seperti halnya subsektor hortikultura (Rachmawan, 2015).

Subsektor hortikultura memiliki peran penting dalam mendukung perekonomian nasional, baik dalam penyediaan produk pangan, kesehatan, perdagangan, penciptaan produk domestik bruto maupun penyerapan tenaga kerja. Komoditas tanaman hortikultura di Indonesia dapat dibagi menjadi tanaman sayuran, tanaman obat, tanaman hias dan tanaman buah-buahan (BPS Indonesia, 2018).
Tanaman jeruk merupakan salah satu komoditas hortikultura. Tanaman jeruk yang dikembangkan di Indonesia adalah peninggalan orang Belanda yang mendatangkan jeruk manis dan Keprok dari Amerika. Jeruk siam (Citrus sp) merupakan salah satu komoditas buah unggulan nasional yang banyak digemari oleh masyarakat Indonesia (Wulandari, 2018).

Sumatera Utara adalah salah satu penghasil jeruk di Indonesia. Pada tabel 1, tahun 2014 produksi jeruk di Sumatera Utara sebanyak 513.858 ton, pada tahun 2015 produksi jeruk di Sumatera Utara mengalami penurunan menjadi 483.006 ton, pada tahun 2016 jumlah produksi jeruk menurun menjadi 467.746 ton, pada tahun 2017 mengalami penurunan drastis menjadi 245.213 ton dan pada tahun 2018 mengalami penurunan lagi menjadi 212.375 
ton.

Tabel 1. Produksi Buah-Buahan Menurut Jenis Tanaman (Ton) Tahun 2014-2018 di Sumatera Utara

\begin{tabular}{|l|l|r|r|r|r|r|}
\hline No & Jenis Tanaman & 2014 (Ton) & 2015 (Ton) & 2016 (Ton) & 2017 (Ton) & 2018 (Ton) \\
\hline 1 & Alpukat & 10.319 & 11.832 & 14.105 & 15.123 & 15.863 \\
\hline $\mathbf{2}$ & Jeruk & $\mathbf{5 1 3 . 8 5 8}$ & $\mathbf{4 8 3 . 0 0 6}$ & $\mathbf{4 6 7 . 7 4 6}$ & $\mathbf{2 4 5 . 2 1 3}$ & $\mathbf{2 1 2 . 3 7 5}$ \\
\hline 3 & Mangga & 31.378 & 32.173 & 21.499 & 24.692 & 26.432 \\
\hline 4 & Rambutan & 28.325 & 24.953 & 17.801 & 15.266 & 16.841 \\
\hline 5 & Duku/ Langsat & 16.715 & 13.868 & 12.326 & 13.289 & 14.811 \\
\hline 6 & Durian & 80.441 & 65.530 & 74.811 & 64.659 & 82.872 \\
\hline 7 & Jambu Biji & 12.661 & 8.806 & 10.049 & 9.807 & 11.382 \\
\hline 8 & Sawo & 8.601 & 7.389 & 9.002 & 11.707 & 9.572 \\
\hline 9 & Papaya & 26.238 & 26.305 & 20.235 & 29.570 & 24.866 \\
\hline 10 & Nenas & 298.901 & 139.541 & 137.886 & 150.691 & 145.617 \\
\hline 11 & Pisang & 237.581 & 223.128 & 163.504 & 160.552 & 118.648 \\
\hline 12 & Salak & 354.087 & 192.585 & 118.619 & 162.622 & 194.454 \\
\hline 13 & Manggis & 10.870 & 7.947 & 7.325 & 9.382 & 7694 \\
\hline 14 & Nangka & 12.818 & 11.018 & 10.253 & 9.971 & 10.880 \\
\hline 15 & Sirsak & 960 & 954 & 1.107 & 932 & 1.360 \\
\hline 16 & Belimbing & 2.941 & 4.028 & 3.453 & 3.894 & 4.410 \\
\hline
\end{tabular}

Sumber : BPS Sumatera Utara, 2018

Pada Tabel 1, menunjukkan bahwa jeruk merupakan buah yang paling banyak diproduksi di Sumatera Utara walaupun setiap tahun terjadi penurunan produksi. Penurunan produksi ini dikarenakan erupsi gunung sinabung di Tanah Karo dan serangan hama penyakit yang yang menyerang tanaman jeruk

Tabel 2. Luas Panen dan Produksi Usahatani Jeruk Setiap Kecamatan di Kabupaten Karo.

\begin{tabular}{|c|l|c|c|c|}
\hline No & Kecamatan & Luas panen (Ha) & Produksi (Ton) & Produktivitas (Ton/Ha) \\
\hline 1 & Mardingding & 137 & 12.724 & 92,88 \\
\hline 2 & Lau Baleng & 388 & 26.358 & 67,93 \\
\hline 3 & Tigabinanga & 21 & 1.033 & 49,19 \\
\hline 4 & Juhar & 22 & 1.310 & 59,55 \\
\hline 5 & Munthe & 874 & 55.663 & 63,69 \\
\hline 6 & Kutabuluh & 115 & 6.661 & 57,92 \\
\hline 7 & Payung & 152 & 6.130 & 40,33 \\
\hline 8 & Tiganderket & 64 & 1.735 & 27,11 \\
\hline 9 & Simpang Empat & 153 & 3.200 & 20,92 \\
\hline 10 & Naman Teran & 363 & 18.500 & 30,96 \\
\hline 11 & Merdeka & 146 & 4.684 & 37,57 \\
\hline 12 & Kabanjahe & 7 & 263 & 24,5 \\
\hline 13 & Berastagi & 70 & 1.715 & 42,30 \\
\hline 14 & Tiga Panah & 681 & 28.808 & 61,71 \\
\hline 15 & Dolat Rakyat & 330 & 20.365 & 36,25 \\
\hline 16 & Merek & 413 & 14.971 & 37,69 \\
\hline 17 & Barusjahe & 219 & 8.255 & 47,14 \\
\hline & Total & 4.153 & 212.375 & \\
\hline & Rara-rata & 244,29 & 12.375 & \\
\hline
\end{tabular}

Sumber: Dinas Pertanian Kabupaten Karo, 2019.

Pada Tabel 2, menunjukkan bahwa Kecamatan Barusjahe merupakan salah satu kecamatan dengan 219 Ha luas panen jeruk siam, produksi sebanyak

\section{METODE PENELITIAN}

Penentuan lokasi penelitian ditentukan secara purposive sampling (sengaja). Lokasi penelitian yang dipilih adalah Desa Sukajulu, Kecamatan
8.255 ton dan produktivitas 37,69 ton/ha (Dinas Pertanian Kabupaten Karo, 2019).

Barusjahe, Kabupaten Karo.Populasi dalam penelitian ini adalah petani yang berusahatani jeruk yang telah berproduksi dan menghasilkan dengan 
umur tanaman 6-12 tahun. Berdasarkan prasurvei, sampel dari penelitian ini adalah sebanyak $33 \mathrm{KK}$. Penentuan sampel dilakukan secara sensus karena semua petani dijadikan sampel penelitian.Data yang dikumpulkan dalam penelitian ini terdiri dari data primer dan data sekunder. Data primer diperoleh dari wawancara langsung dengan petani jeruk di Desa Sukajulu melalui survey kuesioner yang telah dipersiapkan terlebih dahulu. Data sekunder diperoleh melalui instansi terkait seperti, BPS Tanah Karo, Dinas Pertanian, dan situs-situs internet sebagai sumber literatur.Metode analisis data yang digunakan dalam penelitian ini adalah

1. Untuk tujuan (1), metode analisis data yang digunakan dalam penelitian ini adalah model fungsi produksi Cobb-Douglass dengan rumus:

$\mathbf{Y}=\mathbf{a} \mathbf{X}_{1}{ }^{\mathbf{b} 1} \mathbf{X}_{2}{ }^{\mathbf{b} 2} \mathbf{X}_{3}{ }^{\mathbf{b} 3} \mathbf{X}_{4}{ }^{\mathbf{b} 4} \mathbf{X}_{5}{ }^{\mathbf{b 5}} \mathbf{X}_{6}{ }^{\mathbf{b} 6} \mathbf{e}^{\mu}$

Keterangan :

$$
\begin{array}{ll}
\mathrm{Y} & =\text { Produksi }(\text { Ton }) \\
\mathrm{X}_{1} & =\operatorname{Luas} \text { Panen }(\mathrm{Ha}) \\
\mathrm{X}_{2} & =\text { Pupuk NPK }(\mathrm{Kg}) \\
\mathrm{X}_{3} & =\text { Pupuk kandang }(\mathrm{Kg}) \\
\mathrm{X}_{4} & =\text { Insektisida Royal Cyper (L) } \\
\mathrm{X}_{5} & =\text { Insektisida Dafat }(\mathrm{Kg}) \\
\mathrm{X}_{6} & =\text { Tenaga Kerja (HKP) } \\
\mathrm{a} & =\text { Konstanta } \\
\mathrm{bi} & =\text { Besaran yang akan diduga } \\
\mathrm{e} & =\text { Logaritma natural }(2,718)
\end{array}
$$

Kemudian di uji dengan menggunakan uji F:

F Hitung $=\frac{R^{2} / k}{1-R^{2} /(n-k-1)}$

keterangan:

$$
\mathrm{R}^{2} \quad=\text { Koefisien Determinasi }
$$$$
\mathrm{n} \quad=\text { jumlah sampel }
$$

$\mathrm{k} \quad=$ jumlah variabel independen Untuk menghitung $\mathrm{R}^{2}$ digunakan rumus sebagai berikut:

$$
\begin{aligned}
\mathbf{R}^{\mathbf{2}}=\mathbf{1}-\frac{\sum \overline{\boldsymbol{y}}^{\mathbf{2}}}{\sum \boldsymbol{y \boldsymbol { i } ^ { 2 }}}=\mathbf{1}-\frac{\sum \boldsymbol{e i}^{\mathbf{2}}}{\sum \boldsymbol{y \boldsymbol { y } ^ { 2 }}} & \text { keterangan: } \\
\mathrm{y}_{\mathrm{i}} & =\text { variasi yang dijelaskan } \\
\bar{y} & =\text { Rata-rata variasi total y } \\
\mathrm{ei} & =\text { Nilai harapan ke-i }
\end{aligned}
$$

Kriteria uji dengan membandingkan F hitung dengan F tabel.

- $\quad$ F hitung $<\mathrm{F}$ tabel ; hipotesis $\mathrm{H}_{0}$ diterima.

$\mathrm{F}$ hitung $\geq \mathrm{F}$ tabel $:$ hipotesis $\mathrm{H}_{1}$ diterima $\mathrm{H}_{0}$ ditolak (Ghozali,2011).

Uji t dilakukan dengan rumus:

keterangan:

$$
\text { t hitung }=\frac{b i-b}{S b i}
$$

bi = Koefisien variabel ke-i

$\mathrm{b} \quad=$ Nilai hipotesis 0

Sbi = Simpangan baku dari variabel ke-i

Kriteria uji:

t hitung < t tabel maka $\mathrm{H}_{0}$ diterima

$\mathrm{t}$ hitung $\geq \mathrm{t}$ tabel maka $\mathrm{H}_{1}$ diterima $\mathrm{H}_{0}$ ditolak (Soekartawi, 2003).

- Uji Multikolinearitas
Untuk mendeteksi ada atau tidaknya gejala multikolinearitas dapat diperiksa dengan menggunakan nilai variance inflation factor (VIF) dan nilai tolerance. Jika nilai VIF $<10$ dan nilai tolerance $>0,1$ maka tidak terjadi gejala multikolinearitas.

- Uji Heterokedastisitas

Kriteria yang digunakan untuk menyatakan apakah terjadi heteroskedastisitas atau tidak di antara data pengamatan dapat dijelaskan dengan menggunakan koefisien signifikansi. Koefisien signifikansi harus dibandingkan dengan tingkat signifikansi yang ditetapkan sebelumnya (5\%). Apabila koefisien signifikansi lebih besar dari tingkat signifikansi yang ditetapkan, maka dapat disimpulkan tidak terjadi heteroskedastisitas (homoskedastisitas). Jika koefisien signifikansi lebih kecil dari tingkat signifikansi yang ditetapkan,makadapat disimpulkan terjadi heteroskedastisitas (Ghozali,2013).

- Uji Normalitas

Dalam penelitian ini, uji normalitas terhadap residual dengan menggunakan uji KolmogrovSmirnov. Tingkat signifikansi yang digunakan $\alpha$ 0,05 . Dasar pengambilan keputusan adalah melihat angka probabilitas dengan ketentuan: Jika nilai probabilitas 0,05, maka asumsi normalitas terpenuhi atau data berdistribusi normal. Jika probabilitas $<0,05$, maka asumsi normalitas tidak terpenuhi.

2. Untuk tujuan (2), pendapatan bersih dihitung dengan cara mengurangkan total penerimaan dengan total biaya, dengan rumus sebagai berikut:

$$
\text { Pd = TR-TC }
$$

keterangan:

$$
\begin{array}{ll}
\mathrm{Pd} & =\text { Pendapatan bersih } \\
\mathrm{TR} & =\text { Total Revenue }(\text { Total Penerimaan }) \\
\mathrm{TC} & =\text { Total Cost }(\text { Biaya Total) } \\
\text { - Total Penerimaan } &
\end{array}
$$

Untuk mengetahui total penerimaan, dihitung dengan cara mengalikan harga output dengan jumlah produksi.

$$
\mathbf{T R}=\mathbf{P} \times \mathbf{Q}
$$

keterangan:

$$
\begin{array}{ll}
\mathrm{TR} & =\text { Total Revenue (Total Penerimaan) } \\
\mathrm{P} & =\text { Price }(\text { Harga) } \\
\mathrm{Q} & =\text { Quantity (Jumlah) } \\
& \text { - Total Biaya }
\end{array}
$$

Untuk mengetahui total biaya, dihitung dengan menjumlahkan total biaya tetap (total fixed cost) dengan total biaya variabel (total variable cost).

$$
\mathrm{TC}=\mathrm{TFC}+\mathrm{TVC}
$$

keterangan:

$$
\begin{aligned}
& \mathrm{TC}=\text { Total Cost }(\text { Biaya Total) } \\
& \mathrm{TFC}=\text { Total Fixed Cost }(\text { Total Biaya Tetap) } \\
& \text { TVC }=\text { Total Variable Cost (Total Biaya } \\
& \text { Variabel) }
\end{aligned}
$$




\section{HASIL DAN PEMBAHASAN}

Faktor-Faktor Yang Mempengaruhi Produksi Jeruk Siam.

Faktor-faktor produksi yang digunakan petani meliputi luas panen $\left(\mathrm{X}_{1}\right)$, pupuk NPK $\left(\mathrm{X}_{2}\right)$, pupuk kandang $\left(\mathrm{X}_{3}\right)$, insektisida Royal Cyper $\left(\mathrm{X}_{4}\right)$, insektisida Dafat $\left(\mathrm{X}_{5}\right)$, dan tenaga kerja $\left(\mathrm{X}_{6}\right)$. Dari hasil perhitungan fungsi produksi Cobb-Douglas menggunakan SPSS 16.0 diperoleh output sebagai berikut.

Tabel 3. Hasil Pendugaan Koefisien Regresi Terhadap Produksi Usahatani Jeruk dan thitung Pada Tingkat Kepercayaan 95\% $(\alpha=0,05)$

\begin{tabular}{|c|c|c|c|c|c|c|c|c|}
\hline \multicolumn{9}{|c|}{ Coefficients ${ }^{a}$} \\
\hline & \multirow[b]{2}{*}{ Model } & \multicolumn{2}{|c|}{$\begin{array}{c}\text { Unstandardized } \\
\text { Coefficients }\end{array}$} & \multirow{2}{*}{$\begin{array}{c}\text { Standardized } \\
\text { Coefficients } \\
\text { Beta }\end{array}$} & \multirow[b]{2}{*}{$\mathrm{T}$} & \multirow[b]{2}{*}{ Sig. } & \multicolumn{2}{|c|}{ Collinearity Statistics } \\
\hline & & B & Std. Error & & & & Tolerance & VIF \\
\hline \multirow[t]{7}{*}{1} & (Constant) & -.207 & .271 & & -.766 & .451 & & \\
\hline & Luas.Panen & .278 & .102 & .244 & $2.724^{*}$ & .011 & .249 & 4.023 \\
\hline & Pupuk NPK & .148 & .086 & .181 & $1.728^{*}$ & .096 & .183 & 5.451 \\
\hline & Pupuk_Kandang & .061 & .093 & .076 & $.649^{\text {tn }}$ & .522 & .145 & 6.884 \\
\hline & Insektisida Roval Cyper & .201 & .115 & .237 & $1.743^{*}$ & .093 & .108 & 9.268 \\
\hline & Insektisida Dafat & -.014 & .105 & -.016 & $-.130^{\text {th }}$ & .897 & .131 & 7.624 \\
\hline & Tenaga Kerja & .345 & .148 & .321 & $2.339^{*}$ & .027 & .106 & 9.415 \\
\hline
\end{tabular}

Sumber: Diolah dari Lampiran

Keterangan: * = signifikan (nyata) pada tingkat kepercayaan $95 \%$

tn
$\quad \mathrm{R}^{2}=0.948$

$\mathrm{~F}$ hitung $=78,896$
$\mathrm{~F}$ tabel $(0,05) \quad=2.47$
$\mathrm{~T}$ tabel $(0,05) \quad=1.706$

Berdasarkan hasil analisis fungsi produksi CobbDouglas diperoleh persamaan regresi sebagai berikut:

$\log \mathrm{Y}=\log (-0,207)+0,278 \log \mathrm{X} 1+0,148 \log$ $\mathrm{X} 2+0,061 \log \mathrm{X} 3+0,201 \log \mathrm{X} 4-0,014 \log$ $\mathrm{X} 5+0,345 \log \mathrm{X} 6$

Dari hasil perhitungan, nilai koefisien determinasi $\left(\mathrm{R}^{2}\right)$ sebesar 0,948 menunjukkan bahwa 94,8\% variasi variabel dependen (produksi) usahatani jeruk siam dapat dijelaskan oleh variasi variabel independen yang terdapat dalam model. Sedangkan sisanya sebesar $5,2 \%$ variasi variabel dependen dipengaruhi oleh variasi variabel independen lain diluar model.

Uji F digunakan untuk mengetahui pengaruh variabel independen secara serempak terhadap variabel dependen yaitu produksi pada tingkat $\alpha=$ 0,05 dengan $F$ tabel sebesar 2,47. Dari hasil perhitungan memperlihatkan nilai $\mathrm{F}$ hitung lebih besar dari nilai $\mathrm{F}$ tabel pada $\alpha=0,05$ (Fhitung $=$ $78,869>$ Ftabel $=2,47$ ). Hal tersebut menunjukkan bahwa secara serempak variabel independen yaitu luas panen (X1), pupuk NPK (X2), pupuk kandang (X3), insektisida Royal Cyper (X4), insektisida Dafat (X5) dan tenaga kerja (X6) berpengaruh secara signifikan terhadap variabel dependen yaitu produksi jeruk siam (Y). Sesuai kriteria uji yang menyatakan jika Fhitung > Ftabel maka H1 diterima.Dari persamaan fungsi produksi CobbDouglass dengan tingkat kepercayaan sebesar 95\% diperoleh $\mathrm{t}$ tabel sebesar 1,706 maka dapat disimpulkan bahwa luas panen ( $\mathrm{t}_{\text {hitung }} 2,724>\mathrm{t}_{\text {tabel }}$ 1,706), pupuk NPK (thitung 1,728 $>\mathrm{t}_{\text {tabel }} 1,706$ ), insektisida Royal Cyper ( $t_{\text {hitung }} 1,743>t_{\text {tabel }} 1,706$ ), dan tenaga kerja ( $t_{\text {hitung }} 2,399>t_{\text {tabel }} 1,706$ ) secara parsial berpengaruh nyata terhadap produksi jeruk siam di daerah penelitian. Sedangkan pupuk kandang ( $\mathrm{t}_{\text {hitung }} 0,649<\mathrm{t}_{\text {tabel }} 1,706$ ) dan insektisida Dafat $\left(t_{\text {hitung }}-0,130<t_{\text {tabel }} 1,706\right)$ tidak berpengaruh nyata terhadap produksi jeruk saim di daerah penelitian.

Nilai VIF dari luas panen, pupuk NPK, pupuk kandang, insektisida Royal Cyper, insektisida dafat dan tenaga kerja lebih kecil dari 10 dan nilai tolerance lebih besar dari 10 sehingga dapat disimpulkan tidak terjadi gejala multikolinearitas.Pada uji heterokedastisitas seluruh variabel dengan nilai signifikansi $>0,05$ sehingga dapat disimpulkan bahwa tidak terdapat masalah heterokedastisitas. Pada uji normalitas, nilai signifikansi menunjukkan $>0,05$ yaitu sebesar 0,928 artinya asumsi normalitas terpenuhi atau data berdistribusi normal

\section{Pendapatan Bersih Usahatani Jeruk Siam a. Biaya Total Produksi}

Biaya total produksi dalam penelitian terdiri dari biaya sarana produksi, biaya tenaga kerja, biaya PBB, sewa lahan, dan biaya penyusutan alat yang dihitung dalam rupiah. Biaya total produksi yang dikeluarkan oleh petani Jeruk Siam dapat dilihat pada tabel 4 . 
Tabel 4. Biaya Total Produksi Usahatani Jeruk Siam di Desa Sukajulu, Kecamatan Barusjahe, Kabupaten Karo Tahun 2020.

\begin{tabular}{|l|l|c|c|}
\hline \multirow{2}{*}{ No. } & \multicolumn{1}{|c|}{ Uraian } & \multicolumn{2}{|c|}{ Biaya Total Produksi (Rp) } \\
\cline { 3 - 4 } & & Per Petani & Per Hektar \\
\hline 1. & Biaya Variabel: & 9.101 .167 & 17.930 .657 \\
& $-\quad$ Pupuk & 7.432 .333 & 14.642 .806 \\
& $-\quad$ Pestisida & 5.260 .727 & 10.364 .418 \\
\hline 2. & $-\quad$ Tenaga Kerja & 56.000 & 119.149 \\
& Biaya Tetap: & 9.166 .667 & 9.963 .768 \\
& $-\quad$ Biaya PBB/Ipeda & 341.091 & 672.000 \\
\hline & $-\quad$ Biaya Pewa Lahan & 31.357 .985 & 61.779 .911 \\
\hline
\end{tabular}

Sumber: Data Diolah dari Lampiran.

Pada Tabel 4, dapat dilihat biaya total produksi terbesar adalah biaya pupuk sebesar Rp.17.930.657/ha, biaya pestisida sebesar Rp.14.642.806/ha, biaya tenaga kerja sebesar Rp.10.364.418/ha, biaya sewa lahan Rp.9.963.768/ha, biaya penyusutan alat Rp.672.000/ha, dan biaya PBB Rp. 119.149/ha.

\section{b. Produksi Dan Produktivitas Usahatani} Jeruk siam di Daerah Penelitian.

Tabel 5. Luas Panen, produksi dan produktivitas Usahatani Jeruk Siam di Desa Sukajulu, Kecamatan Barusjahe, Kabupaten Karo Tahun 2020.

\begin{tabular}{|l|l|c|c|}
\hline No. & \multicolumn{1}{|c|}{ Uraian } & Satuan & Jumlah \\
\hline 1. & Luas panen rata-rata & $\mathrm{Ha}$ & 0,51 \\
\hline 2. & Produksi rata-rata & $\mathrm{Ton}$ & 8,59 \\
\hline 3. & Harga rata-rata & $\mathrm{Rp} / \mathrm{Kg}$ & 5.500 \\
\hline 4. & Produktivitas & $\mathrm{Ton} / \mathrm{Ha}$ & 16,84 \\
\hline
\end{tabular}

Sumber: Data Diolah dari Lampiran .

Dapat dilihat dari tabel 5 bahwa luas panen ratarata petani jeruk siam seluas 0,51 ha dengan produksi rata-rata sebesar 8,59 ton dengan harga rata-rata jeruk sebesar Rp.5.500 sehingga produktivitas usahatani jeruk siam sebesar 16,84 ton/ha.

c. Pendapatan Bersih Rata-rata Usahatani Jeruk Siam di Daerah Penelitian

Tabel 6. Penerimaan dan Pendapatan Bersih Usahatani Jeruk Siam di Desa Sukajulu, Kecamatan Barusjahe, Kabupaten Karo Tahun 2020.

\begin{tabular}{|l|l|c|c|}
\hline \multirow{2}{*}{ No. } & \multicolumn{1}{|c|}{ Uraian } & \multicolumn{2}{|c|}{ Jumlah (Rp) } \\
\cline { 3 - 4 } & & Per Petani & Per Hektar \\
\hline 1. & Penerimaan & 47.250 .000 & 93.089 .552 \\
\hline 2. & $\begin{array}{l}\text { Biaya } \\
\text { Produksi }\end{array}$ & 31.357 .985 & 61.779 .911 \\
\hline 3. & $\begin{array}{l}\text { Pendapatan } \\
\text { bersih }\end{array}$ & 15.892 .015 & 31.309 .641 \\
\hline
\end{tabular}

Sumber: Data Diolah dari Lampiran.
Tabel 6, menunjukkan bahwa penerimaan usahatani jeruk siam sebesar Rp.93.089.552/ha/tahun. Pendapatan bersih diperoleh dengan mengurangkan penerimaan dengan biaya total produksi. Biaya total produksi pada penelitian ini adalah Rp. 61.779.911/ha/tahun sehingga diperoleh pendapatan bersih usahatani jeruk siam sebesar Rp. 31.309.641/ha/tahun.

\section{KESIMPULAN}

1. Dari hasil perhitungan, nilai koefisien determinasi $\left(\mathrm{R}^{2}\right)$ sebesar 0,948 menunjukkan bahwa $94,8 \%$ variasi variabel dependen (produksi) usahatani jeruk dapat dijelaskan oleh variasi variabel independen yang terdapat dalam model. Sedangkan sisanya sebesar 5,2\% variasi variabel dependen dipengaruhi oleh variasi variabel lain diluar model. Dengan penambahan satu persen jumlah luas panen akan meningkatkan produksi jeruk siam sebesar 0,278 persen (signifikan). Dengan penambahan satu persen jumlah pupuk NPK akan meningkatkan produksi jeruk siam sebesar 0,148 persen (signifikan). Dengan penambahan satu persen jumlah pupuk kandang akan meningkatkan produksi jeruk siam sebesar 0,061 persen (signifikan). Dengan penambahan satu persen jumlah insektisida Royal Cyper akan meningkatkan produksi jeruk siam sebesar 0,201 persen (signifikan). Dengan penambahan satu persen jumlah insektisida Dafat akan menurunkan produksi jeruk siam sebesar 0,014 persen (tidak signifikan). Dengan penambahan satu persen jumlah tenaga kerja akan meningkatkan produksi jeruk siam sebesar 0,345 persen (signifikan).

2. Dari hasil penelitian biaya total produksi sebesar Rp.61.779.911/ha/tahun dengan penerimaan usahatani jeruk siam sebesar Rp.93.089.552/ha/tahun. sehingga diperoleh pendapatan bersih usahatani jeruk siam sebesar Rp.31.309.641/ha/tahun. 


\section{DAFTAR PUSTAKA}

Abd.Rahim. 2007. Ekonomika Pertanian, Pengantar Teori dan Kasus. Penebar Swadaya.

Arikunto, 2006. Prosedur Penelitian Suatu Pendekatan Praktik Edisi Revisi VI. Jakarta: Rineka Cipta.

Badan Pusat Statistik. 2018. Statistik Indonesia Tahun 2018

Badan Pusat Statistik. 2018. Sumatera Utara dalam Angka.

Balitjestro. 2009. Rekomendasi Pemupukan untuk Tanaman Jeruk.

Daniel, Moehar. 2002. Pengantar Ekonomi Pertanian. PT Buni Aksara. Jakarta.

Dinas Pertanian Karo. 2019. Luas di Panen dan Produksi Jeruk Setiap Kecamatan.

Gusti, Hasan. 2018. Analisis Pendapatan Usahatani Jeruk Siam. Banjar. Banjarmasin.

Ghozali, Imam. 2013. Aplikasi Multivariate Dengan Program IBM SPSS 19, Edisi Ketiga, Badan Penerbit Universitas Diponegoro, Semarang.

Handayani. 2006. Ekonomi Pembangunan \& Analisis Data Empiris. Ghalia Indonesia. Bogor.

Hermanto. 1996. Meningkatkan Keunggulan Buah Tropis Indonesia. Yogyakarta.

Irwan Pujo. 2011. Analisis Tingkat Produksi jeruk. Minahasa.

Kusuma, Hadri. 2006. Dampak Manajemen Laba terhadap Relevansi Informasi Akuntansi: Bukti Empiris dari Indonesia.

Mubyarto. 1995. Pengantar Ekonomi Pertanian. LP3ES. Jakarta.

Purwono. M. 2007. Bertanam Jeruk Siam. Penebar Swadaya. Jakarta.

Rachmawan. 2015. Agribisnis Tanaman Hortikultura. Penebar Swadaya. Jakarta.

Rallyanta. 2018. Analisis Pendapatan Daerah Yang Terkena Dampak Gunung Sinabung dan yang Tidak terkena Dampak Gunung Sinabung. IPB: Bogor.

Rismunandar. 1986. Bercocok Tanaman Jeruk. Sinar Baru. Bandung.

Salikin KA. 2003. Sistem Pertanian Berkelanjutan. Yogyakarta.

Setiawan, A. 1992. Jeruk Siam. Penebar Swadaya. Jakarta.

Shinta, A. 2011. Ilmu Usahatani. Universitas Brawijaya Press, Malang.

Singarimbun. 1989. Metode penelitian suvey. LP3ES. Jakarta.

Soekartawi. 1990. Teori Ekonomi Produksi Dengan Pokok Bahasan Analisis Fungsi CobbDouglass. PT. Raja Grafindo Persada. Jakarta.

2002. Analisis Usahatani. Universitas Indonesia. Jakarta.
2003. Prinsip Ekonomi Pertanian. Rajawali Press. Jakarta.

Sugiatno. 2019. Dampak Erupsi Gunung Sinabung Terhadap Pertumbuhan Tanaman Jeruk Di Kabupaten Karo, Sumatera Utara. Perpustakaan Balitjestro.

Wahyu. 2019. Faktor-Faktor Yang Mempengaruhi Produksi Jeruk Siam. Universitas Jambi.

Wanda, Faisal. 2015. Analisis Pendapatan Usahatani Jeruk Siam di Desa Padang Pangrapat. Universitas Mulawarman. Kalimantan Timur.

Wulandari. 2018. Pengaruh Modal, Tenaga Kerja, dan Lama Usaha terhadap Pendapatan. Universitas Udayana. Bali. 